\title{
RESEARCH
}

Open Access

\section{Environmental and landscape influences on the spatial and temporal distribution of a cattle herd in a South Texas rangeland}

\author{
Christopher Cheleuitte-Nieves ${ }^{1,2^{*}} \mathbb{D}$, Humberto L. Perotto-Baldivieso ${ }^{3}$, X. Ben $\mathrm{Wu}^{1}$ and Susan M. Cooper ${ }^{4}$
}

\begin{abstract}
The multiple spatial and temporal parameters affecting cattle herd distribution and activity dynamics can significantly affect resource utilization but are not fully understood. The aim of this study was to determine whether current animal tracking technology and spatio-temporal analysis tools can be used to integrate multi-scale information on herd distribution patterns as a function of seasonal forage production, periods of the day, animal activity, and landscape features. Positional and activity information of 11 free-ranging cows within a 31-member herd was obtained at 5-min intervals by using GPS collars for 1 year within a 457-ha ranch in the semi-arid rangelands of South Texas. Forage biomass was calculated with satellite imagery. Spatial analysis of cattle distribution and landscape features was conducted with GIS.

Herd spread was greatest during the growing season. Throughout the year, during midday, the herd showed smaller spread and greater use of shade patches than any other time of day. Cattle also aggregated under trees in winter, particularly during the night. There was no statistically significant overall pattern of seasonal changes in the use of water and supplemental feeding areas, but a trend toward highest use during the winter. However, significantly different diurnal patterns in the use of supplemental feed and water were observed within each season.

This study found a strong influence of shade patches relative to the influence of water and supplemental feeding areas on the diurnal and seasonal movement patterns of cattle in shrub-dominated rangeland. Although this study used only 11 tracked cows in a 31-member herd, the results indicated that techniques such as seasonal and diurnal GPS tracking, GIS, and remote sensing data enable evaluation of multiple spatial and temporal dynamics of cattle distribution and activity patterns. The smaller spread during the dry winter season associated with the observed aggregation of individuals in water and supplemental feeding areas, may aid in determining the most critical times for providing supplemental resources and guide the allocation of those resources to areas not frequently used by cattle, thus stimulating the animals to visit unused sites during the non-growing season.
\end{abstract}

Keywords: Cattle behavior, Cross-scale interactions, GPS collars, Group dispersion, Normalized difference vegetation index (NDVI), Thermoregulation, Ungulate grazing patterns

\footnotetext{
* Correspondence: cheleuic@mskcc.org

'Department of Ecosystem Science and Management, Texas A\&M University,

2120 TAMU, 320 WFES Building, College Station, TX 77843-2138, USA

${ }^{2}$ Present address: Center of Comparative Medicine and Pathology, Memorial

Sloan Kettering Cancer Center, Weill Cornell Medicine, and Hospital for

Special Surgery, 408 East 69th Street, Z-913, New York, NY 10021, USA

Full list of author information is available at the end of the article
}

\section{Springer Open}

(๑) The Author(s). 2020 Open Access This article is licensed under a Creative Commons Attribution 4.0 International License, which permits use, sharing, adaptation, distribution and reproduction in any medium or format, as long as you give appropriate credit to the original author(s) and the source, provide a link to the Creative Commons licence, and indicate if changes were made. The images or other third party material in this article are included in the article's Creative Commons licence, unless indicated otherwise in a credit line to the material. If material is not included in the article's Creative Commons licence and your intended use is not permitted by statutory regulation or exceeds the permitted use, you will need to obtain permission directly from the copyright holder. To view a copy of this licence, visit http://creativecommons.org/licenses/by/4.0/. 


\section{Introduction}

Given the current critical status of habitat degradation and loss, species invasion, and global climate change, there has been great interest in more accurate, explicit studies identifying factors affecting species distribution (Ritchie et al. 2009; Butt 2010). Ungulates play essential roles in natural environments, where they shape the vegetation composition and structure and influence ecosystem function, and in managed settings, where they provide resources to human populations (Butt 2010; Goheen et al. 2010). Developing better predictive models of ungulate movement patterns is important in assessing the relationships among species distribution, ecosystem change, and pastoralist livestock operations (Butt 2010). Ungulate behavior is influenced by landscape structures and resources, as well as the interaction of ecological processes occurring at different spatial and temporal scales (Hinch et al. 1982; Senft et al. 1987; Bailey et al. 1996; Johnson et al. 2002; Seagle and McNaughton 1992; Weladji et al. 2002; Bailey 2004, 2005; Peters et al. 2004, 2006; Stephenson et al. 2016; Stephenson and Bailey 2017; Cheleuitte-Nieves et al. 2018). Therefore, flexible and opportunistic nutritional and physiological strategies can be developed on the basis of this spatio-temporal variability, thus producing distinct spatial distribution patterns in wildlife and livestock, and in natural and managed settings (Scoones 1995; Seagle and McNaughton 1992; Parker et al. 2009). Wild and domestic ungulate herds grazing in arid and semi-arid rangelands exhibit uneven grazing distribution, owing to the animals' tendency to select areas of highly palatable forage near critical resources such as water (Belovsky 1984; Frixell 1991; Scoones 1995; Wallace et al. 1995; Cooper et al. 2006, 2008; Parker et al. 2009). Particularly in riparian zones, uneven pasture use can result in soil erosion, degradation of vegetation, bacterial contamination of water bodies, diminished economic returns, and increased supplemental feed costs (Turner et al. 2000; Ganskopp 2001; Launchbaugh and Howery 2005; Harris et al. 2007; Butt 2010). Therefore, the activities and spatial distribution of large herbivores are influenced by environmental conditions and processes occurring at different scales, and their activities and distribution can consequently affect patterns of ecosystem structure and function (Goheen et al. 2010).

Although previous studies have explored important abiotic (e.g., slope, distance to water) and biotic (e.g., animal species, forage abundance, and quality) factors influencing large herbivore movement, the effects of relationships and interactions of processes occurring at different temporal scales on ungulate herd distribution dynamics have not been fully explored. Biological systems are complex, and processes occurring at different scales jointly influence the system and consequently affect animal behavior in unique ways (Johnson et al. 2002; Peters et al. 2004, 2006). Hence, examination of the multi-scale interaction of system processes might provide novel insights into the factors and processes affecting animal movement dynamics and aid in the development of better predictive models of animal distribution and their effects on the environment (Bailey 1995; Ritchie et al. 2009; Cheleuitte-Nieves et al. 2018). Furthermore, many of these studies have been conducted in northwestern mountainous rangelands of North America and montane cold regions of Europe. In contrast, the Southern Plains in North America have gentle terrain and very different temperature, precipitation, and vegetation production regimes from those in the northwest (Taylor et al. 1999), as well as different factors potentially influencing cattle distribution. Explicit spatio-temporal analyses at multiple scales are needed to better understand these relationships and, in the case of livestock, to develop more effective management techniques that promote better distributed pasture use (Launchbaugh and Howery 2005).

Ungulate distribution studies are usually based on field observations of several animals, and analyses of movement patterns are difficult to measure (Stricklin 1983; Turner et al. 2000, 2001; Harris et al. 2007). These studies have limited accuracy, few to no replications, and almost no night time observations. For example, Stephenson et al. (2016) have shown that herd size appears to influence association patterns among members of cattle herds. They have detected no strong or weak association patterns in herds of 40 cows or fewer through visual observations; however, in groups larger than 40 animals, herds tend to show subgrouping behavior and use different parts of the pasture. To better understand the relationship between landscape characteristics and animal movement dynamics, tracking technology such as global positioning systems (GPS) integrated with geographical information systems (GIS) and remote sensing techniques have been used (Ganskopp et al. 2000; Turner et al. 2000, 2001; Ungar et al. 2005; Butt 2010). These advances in geospatial data acquisition allow for precise tracking of animal distribution and landscape characteristics, which can provide new information useful for more accurate ethological studies and investigations of the responses to landscape structure and changes in the environment (Ungar et al. 2005). For example, when long-term field measurements of biomass availability are not available, remotely sensed estimates can serve as a viable alternative (Butt 2010). Vegetation indices, derived from various satellite platforms and sensors, are dimensionless, radiometric measures that indicate the relative abundance and biological activity of green vegetation on the basis of the differential brightness between the red and near-infrared bands 
(Jensen 2005). The Normalized Difference Vegetation Index (NDVI) is considered "the most robust indicator of available forage biomass" used in many ecosystems to determine the spatio-temporal variability of vegetation resources (Butt 2010). Furthermore, it has been used for more than 30 years throughout sub-Saharan Africa and has been described as the most reliable vegetation index of the dried biomass characteristics of savanna ecosystems (Martiny et al. 2005, 2006; Butt 2010). Remotely sensed environmental data coupled with the GPS locations of animal distribution patterns have been demonstrated to be useful for uncovering the grazing dynamics of both wild ungulates and domestic livestock in various environments (Bailey et al. 1996; Ganskopp 2001; Ungar et al. 2005; Butt 2010). Given that forage biomass is a major factor influencing large herbivore movement, the NDVI should be beneficial in assessing how seasonal changes in forage relate to patterns of ungulate use of landscape structures and resources in a brushy savanna (Senft et al. 1987; Sowell et al. 1999).

Free-ranging beef cattle, Bos taurus, are a good model for empirical testing of large herbivore herd movement patterns (Reinhardt 1983; Šárová et al. 2010) because they behave similarly to natural, wild herds when human interference is minimal, while allowing for ease of handling (Reinhardt 1983). The goal of this study was to determine whether current animal tracking technology (i.e., GPS collars and activity sensors) and spatiotemporal analysis tools (i.e., GIS and remote sensing) might be used to better understand how landscape characteristics affect the spatial distribution of a cattle herd in a semi-arid rangeland, as well as the factors influencing herd spread as a function of multiple temporal scales. The specific objectives were to (1) examine the patterns of herd spread as a function of seasonal forage production, periods of the day, and animal activity schedules, (2) determine the degree of seasonal use of shade patches by cattle at different periods of the day, and (3) determine the seasonal and diurnal influences of water and supplemental feeding locations on cattle distribution patterns. We hypothesized that seasonal changes in forage availability and diurnal changes in temperature would affect herd spread and animal activity. More specifically, we expected the herd to congregate more and spend more time around supplemental feeding and water areas during the dry season and around shade patches during midday (i.e., under higher ambient temperatures). Examination of the spatial and temporal patterns of herd distribution and associated environmental factors can improve understanding of the factors and processes influencing herd spatial distribution and potential cross-scale interactions. Furthermore, an improved understanding of herd behavior could potentially guide the enhancement of management regimes aiming to manipulate spatial patterns, enhance animal comfort, increase production efficiency, and be more compatible with animal behavior (Stricklin 1983).

\section{Methods \\ Study area}

The rangelands of the southern USA are part of the subtropical savanna and shrubland biome, which also include areas of South America, Africa, Australia, and India (Ricklefs 2001). The study site was a 457-ha ranch in Uvalde County, Texas (lat $29^{\circ} 19^{\prime} 8.584^{\prime \prime} \mathrm{N}$, long $99^{\circ} 42^{\prime} 54.161^{\prime \prime}$ W; Fig. 1), located in the South Texas Plains Ecoregion near the transition zone to the Edwards Plateau. The topography is mostly level, with gentle undulating planes (Taylor et al. 1999). This area has a semi-arid climate characterized by dry winters and hot, humid summers (United States Department of Agriculture 1976). The mean annual precipitation is $406 \mathrm{~mm}$, and there are substantial inter-annual variations (Perotto-Baldivieso et al. 2012). More than two-thirds of the precipitation occurs during the warm season from May through October, and the highest amount of rainfall is usually in May, which is followed by a second rainfall peak in September. The mean temperatures range from $2.9^{\circ} \mathrm{C}$ in the winter to $36.7^{\circ} \mathrm{C}$ in the summer. The growing season lasts 340 to 360 days.

Soils in the west part of the ranch are mostly Montell clay characterized by gently sloping ( 0 to $3 \%$ slope), deep, calcareous soils formed in clayey alluvium on outwash plains (Clay Flat range site; USDA 1976). Soils in the eastern part of the ranch are mostly undulating Olmos on low ridges characterized by shallow calcareous soils formed in beds of caliche (Shallow Ridge range site). The ranch is externally fenced and has no natural water sources but has three dispersed water troughs and a large pond at the southeast part of the ranch. There is a network of dirt roads to facilitate cattle and deer management. The property was under a continuous yearlong grazing schedule with a stocking rate of $15 \mathrm{ha} / \mathrm{AU}$. Supplemental feed operations occurred at least three times per week between 10:00 and 15:00 at one location per feeding time (Fig. 1). The supplement consisted of $20 \%$ (crude protein) breeder range cubes, a feed for mature beef cattle on pasture. This system provided no resting period for vegetation, and herds were hay-fed (Sorghum almum $\times$ S. drummondii; $10.8 \%$ crude protein, $42 \%$ acid detergent fiber, $68 \%$ neutral detergent fiber, $56 \%$ total digestible nutrients, $0.46 \%$ calcium, $0.21 \%$ phosphorus, dry matter basis) year-round.

The study area had $29.4 \%$ woody cover composed of low-growing, thorny vegetation that formed dense mottes of small trees and shrubs with a grassland matrix. Small live oak trees (Quercus virginiana) formed mottes scattered throughout the landscape, which were 


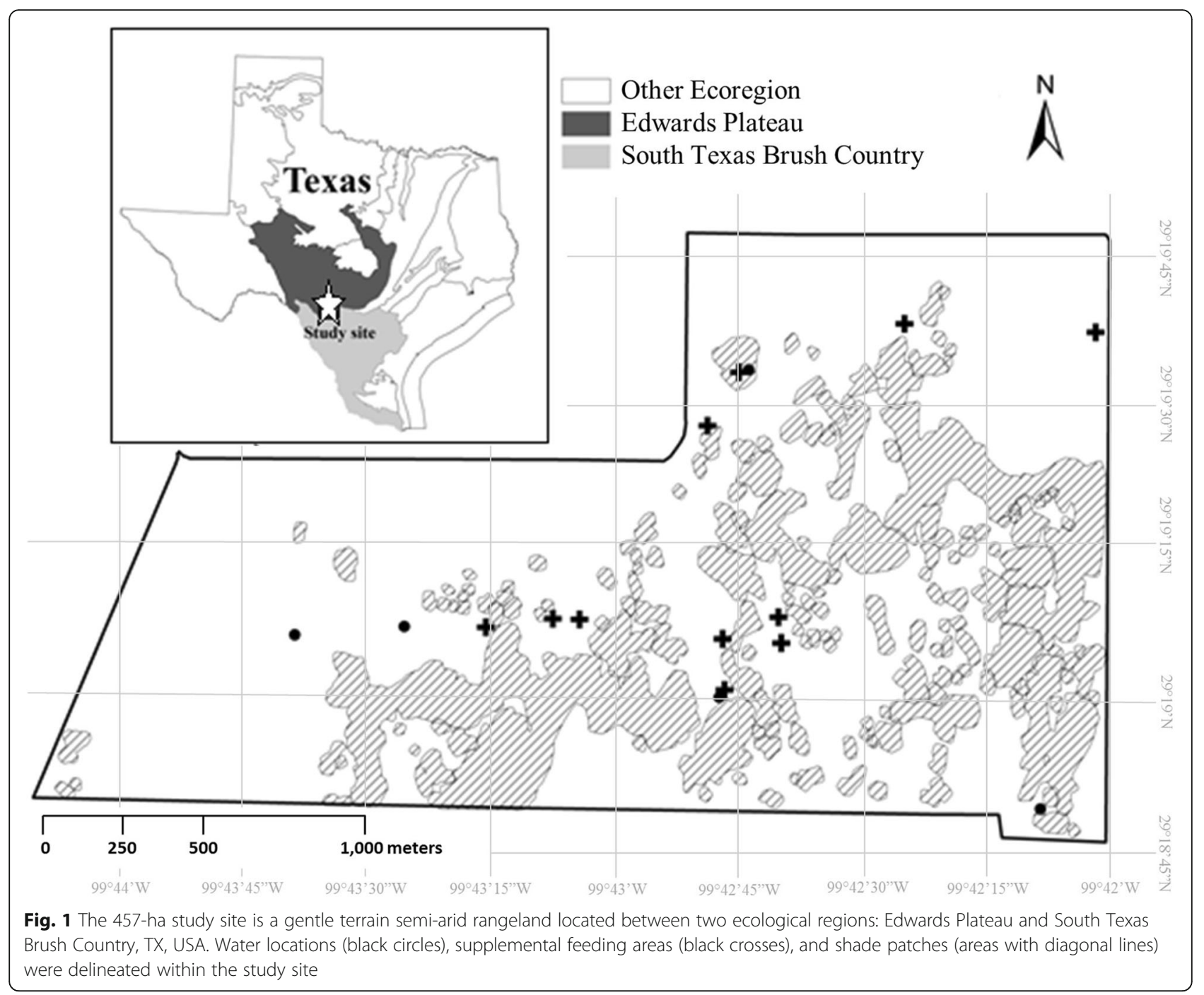

surrounded by a diverse variety of shrubs. The dominant shrubs were catclaw acacia (Acacia greggii), twisted acacia (Acacia schaffneri), agarita (Mahonia trifoliate), spiny hackberry (Celtis palida), and succulents such as Texas pricklypear (Opuntia engelmannii), tasajillo (Opuntia leptocaulis), and Yucca spp. Forbs provided a diverse but ephemeral food resource. Common grasses were Halls panicum (Panicum hallii), hairy tridens (Erioneuron pilosum), common curlymesquite (Hilaria belangeri), Texas grama (Bouteloua rigidiseta), sideoats grama (Bouteloua curtipendula), threeawn (Aristida spp.), plains bristle grass (Setaria leucopila), slim tridens (Triden muticus var. muticus), red grama (Bouteloua trifida), and Texas wintergrass (Nassella leucotricha) (Cooper et al. 2008; Perotto-Baldivieso et al. 2012).

\section{Animal selection and GPS collars}

To achieve the aim and objectives of this research, we used a small herd of 31 free-ranging Angus $\times$ Bonsmara cows (Bos taurus). Telemetry collars containing GPS receivers and dual axis activity sensors (Lotek GPS 3300LR; Lotek Engineering, Newmarket, Ontario, Canada) were placed on 11 randomly selected individuals from this herd. In this study, similarly to previous studies, only 11 individuals were used because of the limited availability and high cost of GPS collars used to collect movement data (Shiyomi and Tsuiki 1999; Gankskopp 2001; Johnson et al. 2002; Harris et al. 2007; Cooper et al. 2008; Šárová et al. 2010). The cows were between 4 and 6 years of age during the study period, had a mean weight of $1193 \mathrm{~kg} \pm 38.4 \mathrm{SE}$, and a body condition score of 2.5/5. Current calving management practices were maintained where cows calved during the spring and calves were present during the summer season. The 11 selected individuals and their GPS collars were kept constant throughout the study. Animals were handled according to the Texas A\&M University Institutional Animal Care and Use Committee Animal Use 
Protocol (Animal Use Protocol [AUP] \#2007-167). The GPS collars provided information on the location, date, time, ambient temperature, and animal activity on two axes. The location was accurate to within $2 \mathrm{~m}$ after differential correction (Lotek 2006). The dual axis motion sensors were sensitive to vertical (fore-aft) and horizontal (left-right) movements of the head and neck and recorded the number of times that a switch was triggered during the 4 min preceding a GPS fix (Coulombe et al. 2006). Every $5 \mathrm{~min}$, the activity data for both axes were stored in the collar's memory.

\section{Sampling period and data processing}

The operational schedule for the collars was set for a GPS fix interval of $5 \mathrm{~min}$ and an activity-sampling period of $4 \mathrm{~min}$. Positional and activity data were recorded at synchronized fix intervals for all 11 individuals for 21 days per trial. Predictive models with GPS fix intervals of $5 \mathrm{~min}$ are more appropriate and effective than larger intervals in determining and separating activities (Ungar et al. 2005). Turner et al. (2000) have reported greater error if the GPS fix interval is increased from 5 to 30 $\mathrm{min}$ and have suggested that intervals greater than $5 \mathrm{~min}$ may be unable to identify certain types of data, such as discrete watering events or accurate interpretation of animal activity. Ganskopp (2001), in a study using 20min resolution, has also concluded that adequate modeling of activities may require more frequent sampling intervals. The collars were also equipped with a wide range temperature transducer that measured and recorded ambient temperature with an accuracy of $\pm 1{ }^{\circ} \mathrm{C}$ within the operating temperature of the collar. We used the average temperature from all collars to obtain diurnal and seasonal ambient temperatures. Two sampling trials per season (i.e., autumn, winter, spring, and summer) were conducted, to account for within season variability, thus resulting in a total of eight trials from September 2007 to August 2008. At the end of each period, all data were retrieved from the collars and differentially corrected with N4 v.1.2138 differential postprocessing software (Lotek 2006) and the Del Rio station as the base location (National Oceanic and Atmospheric Administration 2007). When differential corrections were not possible (e.g., there were no data from the base station), an uncorrected position was used $(<20$ data points per trial). When no collar integration was obtained, a series of three consecutive records was interpolated to complete the data set (Ganskopp and Johnson 2007). If more than three successive fixes were not obtained, that portion of the dataset was omitted from analysis (Cheleuitte-Nieves et al. 2018).

Four periods of the day were selected to capture the diurnal variation in animal behavior according to past research (Gary et al. 1967; Stricklin et al. 1976; Scoones
1995; Ganskopp 2001; Parsons et al. 2003). The periods were (1) early morning (grazing bout), the first $3 \mathrm{~h}$ after sunrise; (2) midday (resting bout), the $3 \mathrm{~h}$ around the solar noon; (3) late afternoon (grazing bout), the last $3 \mathrm{~h}$ before sunset; and (4) midnight (resting bout), the $3 \mathrm{~h}$ around the time opposite of solar noon. Data were processed with ArcGIS 9.x (ESRI, Redlands, CA) to convert the differentially corrected data (latitude/longitude form) to the Universal Transverse Mercator (UTM 14-N) coordinate system to allow for the algebraic derivation of straight-line distances between successive GPS fixes (Ungar et al. 2005).

\section{Animal activity}

Field work was conducted to observe the behavior of each collared animal to calibrate the activity sensor data, as recommended by Ungar et al. (2005). A total of 300 field observations were made during early morning and late afternoon because those are periods of greater activity variation and shifts (Bailey 1995). Data collection occurred throughout all study seasons, and the length period varied from 4 to $8 \mathrm{~h}$, depending on the movement and visibility of the animals. One to three observers were available at any particular observation period, each of whom was assigned three to four study animals. The recorded activities were grazing (including walking while grazing as long as the head was down to the vegetation), traveling (walking movement), and resting (no walking movement with animal either lying or standing). The type of activity and amount of time were tallied on data sheets by recording the start time of each activity during the sampling period (Ganskopp 2001). Observational data were later synchronized with the sensor data from each individual for further analyses.

The simultaneous procedure for discrimination analyses proposed by Ungar et al. (2005) was used to infer animal activity. This methodology uses activities divided into three distinct classes: left-right motion sensor count, fore-aft motion sensor count, and the distance between GPS fixes and observed activities. The distance between GPS fixes was calculated as the Euclidean distances $(\mathrm{m})$ between successive locations. Although the distance between successive locations was accurate to 2 $\mathrm{m}$, that measure underestimates the animals' actual travel because the calculations assume straight-line travel (Ungar et al. 2005). Additional analyses were conducted to characterize animal activity at the herd scale (i.e., $\geq 6$ out of 11 GPS collared animals engaged in the same activity during the same time interval) as a function of season, time of the day, and associated temperature fluctuations. Significant differences in mean discriminant function scores were identified with Wilks' Lambda statistic (SPSS Statistics, Rel. 11.0.1, SPSS Inc., Chicago, IL, USA). 


\section{Herd spread}

To understand cattle grouping behavior and degree of dispersion, we determined the spread by using the distance from the group center (Stricklin 1983; Waser 1985; Kunz and Hemelrijk 2003; Wolfram Research 2007). The mean distance of all individuals to the center of gravity of the herd for each time interval was used to represent the spread of the herd at that time. The center of gravity of the herd was calculated by averaging the $X$ and $Y$ coordinates of the 11 individuals for each GPS fix. The Euclidean distance from each individual to the center of the herd was then calculated. However, spatial data with successive records separated by short time intervals (e.g., 5 min intervals) and the non-random movement of animals can produce autocorrelated data with redundant information that violates statistical independence (Swihart and Slade 1997; de Solla et al. 1999; Weber et al. 2001). Perotto-Baldivieso et al. (2012) have reported that $120 \mathrm{~min}$ intervals between GPS fixes can significantly decrease autocorrelation; therefore, we sampled the data to $120 \mathrm{~min}$ intervals for our seasonal spread analysis by randomly selecting the first data location and then obtaining the rest of the locations by using the appropriate interval length. In contrast, for diurnal and activity spread analysis, we used a 5-min GPS fix interval to obtain sufficient data for the different time periods and capture most of the activity events. Our activity analyses showed that not all animals had the same activity within the same time period, thus decreasing the potential for individual correlation among individuals. Spread calculations were summarized to estimate the mean and standard error for all trials. Mean comparisons were conducted to examine the overall seasonal and diurnal patterns of herd spread, as well as the seasonal patterns of herd spread as a function of time of the day and activities. The Kruskal-Wallis one-way analysis of variance on ranks test was used to examine statistical differences in the mean spread of the herd across seasons, time periods, and activities.

\section{Estimation of available forage biomass with NDVI}

Vegetation shows differential brightness in the red and near-infrared parts of the electromagnetic spectrum (Gates 1970; Ahmad 2012). We estimated and compared the NDVI as an indicator of seasonal changes in the amount of forage biomass (Mbow et al. 2013; Birtwistle et al. 2016; Roy et al. 2016). For each season, we acquired one Landsat 7 ETM+ scene (Path 28, Row 40) from the US Geological Survey (United States Geological Survey 2010): Earth Resources Observation and Science Center (EROS). Landsat scenes have a spatial resolution of $30 \mathrm{~m}$ for bands 1 through 5 and 7, and a temporal resolution of 16 days. We focused our analyses on bands 3 and 4 (red and near infrared). Because cattle herd GPS data collection was conducted from September 2007 to August 2008, for autumn, we used a Landsat scene from November 2, 2007 with $0 \%$ cloud cover. For winter, we used a scene from February 6, 2008 with 0\% cloud cover. For spring, we used a scene from April 10, 2008 with 7\% cloud cover. Finally, for summer, we used a scene from July 15, 2008 with 0\% cloud cover. Downloaded scenes were already processed via Standard Terrain Correction (Level $1 \mathrm{~T}$ ), which provides systematic radiometric and geometric accuracy by incorporating ground control points while using a Digital Elevation Model for topographic accuracy (United States Geological Survey 2010). After the scenes were decompressed, we used the ENVI v.4.7 (2009; ITT Visual Information Solutions, Boulder, $\mathrm{CO})$ software for processing and analysis of the geospatial imagery.

Because solar radiation passes through the atmosphere before it is collected by the sensor during remote sensing, the images include information about the atmosphere and the Earth's surface (Atmospheric correction module v. 4.7; ITT 2009). To accurately analyze surface reflectance, removing the influence of the atmosphere (e.g., scattering and absorption) is important during preprocessing (Jensen 2005). We used Fast Line-of-sight Atmospheric Analysis of Spectral Hypercubes (FLAASH) developed by Spectral Sciences, Inc., an atmospheric correction modeling tool for retrieving spectral reflectance from multispectral radiance images. The FLAASH extension in ENVI is a first-principle atmospheric correction tool that corrects wavelengths in the visible through near-infrared and shortwave infrared regions, up to $3 \mu \mathrm{m}$, and incorporates the MODTRAN4 radiation transfer code and computes a unique solution for each image.

To meet the input requirements for FLAASH, we first used the ENVI Landsat Calibration and Band Math tools to calibrate the image in radiance units of $\mu \mathrm{W} / \mathrm{cm}^{2} \times$ $\mathrm{nm} \times$ sr. Then we used the Layer Stacking tool to make all bands one layer and used the Convert Data tool to convert the layer into the band interleaved by line format. Because the input image was already correctly scaled, we used a single scale factor for all bands. Latitude, longitude, sensor type, flight date, and flight time were specified for each image according to the metadata file provided with the scenes. For the atmospheric model, we used "Mid-latitude summer" and "Mid-latitude winter" (Table 1). We also used Kaufman-Tanre aerosol retrieval, which estimates a scene average visibility with the dark pixel reflectance ratio method.

Finally, after each image was atmospherically corrected, surface reflectance was obtained and used to calculate NDVI with ENVI. Mean comparisons were conducted to examine the overall seasonal patterns of NDVI changes as an indicator of seasonal forage 
Table 1 Column water vapor amounts and surface temperatures for the MODTRAN model atmosphere

\begin{tabular}{llll}
\hline Model atmosphere & Water vapor $(\mathrm{std} \mathrm{atm}-\mathrm{cm})$ & Water vapor $\left(\mathrm{g} / \mathrm{cm}^{2}\right)$ & Surface air temperature $\left({ }^{\circ} \mathrm{C}\right)$ \\
\hline Mid-latitude summer (MLS) & 3636 & 2.92 & 21 \\
Mid-latitude winter (MLW) & 1060 & 0.85 & -1 \\
\hline
\end{tabular}

biomass fluctuations. One-way analysis of variance $(\alpha=$ $0.05)$ was used to examine statistical differences among the NDVI results of atmospherically corrected images for each season.

\section{Analysis of shade patches and water and supplemental feed areas}

Shade patches were delineated with a $2-m$ resolution 2006 aerial photograph (Texas Natural Resources Information System, 2008) and ArcMap 9.3 to create a shade polygon vector layer of tree patches (Fig. 1). A 10-m buffer was created around all shade patches to compensate for GPS fix error and shade extent beyond the patch edge. Locations of water and feeders were plotted with a sub-meter accuracy GPS unit (Trimble GeoXT, Sunnyvale, CA). We defined use as the average number of GPS fixes per day per trial that met the specified selection criteria. A 30-m buffer was created around water and supplemental feeding locations. The $30-\mathrm{m}$ buffer was selected on the basis of the locational error of GPS instruments, size of the herd, and field observations (estimated spread of the group during feeding and watering events) with an aim of avoiding overlap among features (Cooper et al. 2010). $X$ and $Y$ data from the GPS collars were added and exported to create a layer of all GPS fixes for each trial. Data were selected according to the analyzed features, divided into the four time periods, and then clipped to obtain only the GPS fixes within the features via ArcMap 9.3.

The number of GPS fixes per feature, trial (season), and period of the day were summarized to estimate the mean and standard error. Mean comparisons were conducted to examine the overall seasonal and diurnal patterns of use. Kruskal-Wallis one-way analysis of variance on ranks $(\alpha=0.05)$ was used to examine statistical differences in the average number of GPS fixes per day for shade patches and water and supplemental feeding areas.

\section{Results}

\section{Detection of animal activity by collar variables}

Resting, grazing, and traveling activities accounted for $28 \%, 48 \%$, and $24 \%$ of the observations, respectively. Useful discriminant functions were found for the leftright motion (Wilks' Lambda $=0.804, F=36.250, P<$ 0.0001), fore-aft motion (Wilks' Lambda $=0.909, F=$ 14.814, $P<0.0001$ ), and distance between fixes (Wilks' Lambda $=0.501, F=148.113, P<0.0001)$. Discriminant analysis of animal activity (grazing, resting, and traveling) according to the collar variables yielded a correct classification rate of 73\% (Wilks' Lambda $=0.403, P<$ 0.0001 ). Specifically, $29 \%$ of the resting activity was misclassified as grazing, and $22 \%$ of the traveling activity was misclassified as grazing (Table 2). On the basis of the small significant Wilks' Lambda and the plotted activity/collar variable relationships, the distance variable appeared to be the best predictor of animal activity, followed by the left-right motion sensor.

Resting was generally characterized by values less than 100 in the left-right sensor count and less than $30 \mathrm{~m}$ in the distance variable. Grazing and traveling appeared to be associated with high values $(>100)$ of the left-right sensor counts. Grazing predominated at intermediate values $(10-100 \mathrm{~m})$ and values for traveling at large distance $(>100 \mathrm{~m})$. The variable of distance between GPS fixes separated most of the resting and traveling activities when plotted against the other two collar variables: the left-right motion sensor count (Fig. 2a) and the foreaft motion sensor count (Fig. 2b). Using the relationship between the left-right and fore-aft sensor counts alone did not strongly separate any of the activities (Fig. 2c).

\section{Seasonal and diurnal activity schedules at the herd scale} At the seasonal scale, all trials showed a higher percent of resting activity per day compared to grazing and traveling activities (Fig. 3). Traveling accounted for the lowest frequency of occurrence among all three activities throughout the year. At the diurnal scale, two grazing periods and two resting periods were identified for all eight trials (Fig. 4). Overall, the resting periods occurred at approximately 11:00-15:00 and 21:00-6:00 (next day) and the grazing periods occurred at approximately 6:0011:00 and 15:00-21:00. Smaller amounts of traveling activity occurred throughout the day and mostly occurred at the beginning and throughout grazing periods.

Table 2 Frequency count and percentage of field observed activities in the predicted activity categories according to discriminant analysis

\begin{tabular}{lllll}
\hline $\begin{array}{lllll}\text { Observed } \\
\text { activity }\end{array}$ & \multicolumn{2}{l}{ Predicted activity } & \multirow{2}{*}{$\begin{array}{l}\text { Total } \\
\text { count }\end{array}$} \\
\cline { 2 - 4 } Resting & Grazing & Traveling & \\
\hline Resting & $60(70.6 \%)$ & $25(29.4 \%)$ & $0(0 \%)$ & 85 \\
Grazing & $22(15.4 \%)$ & $111(77.6 \%)$ & $10(7 \%)$ & 143 \\
Traveling & $9(12.5 \%)$ & $16(22.2 \%)$ & $47(65.3 \%)$ & 72 \\
\hline
\end{tabular}


a.

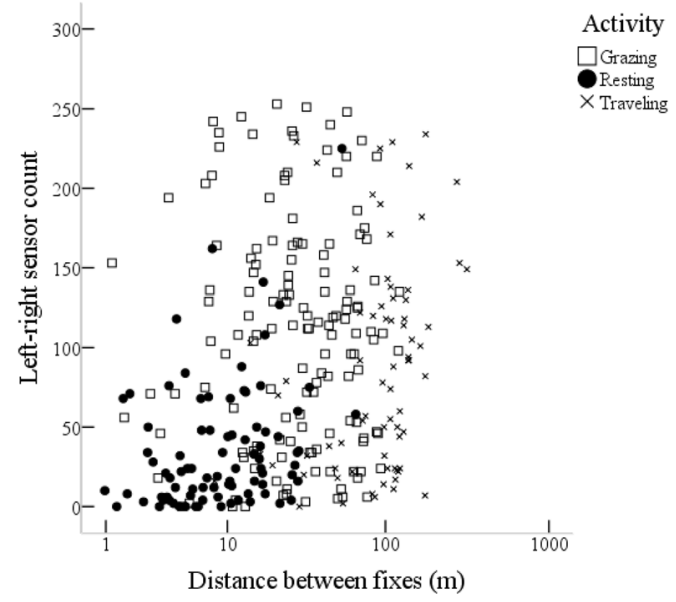

b.

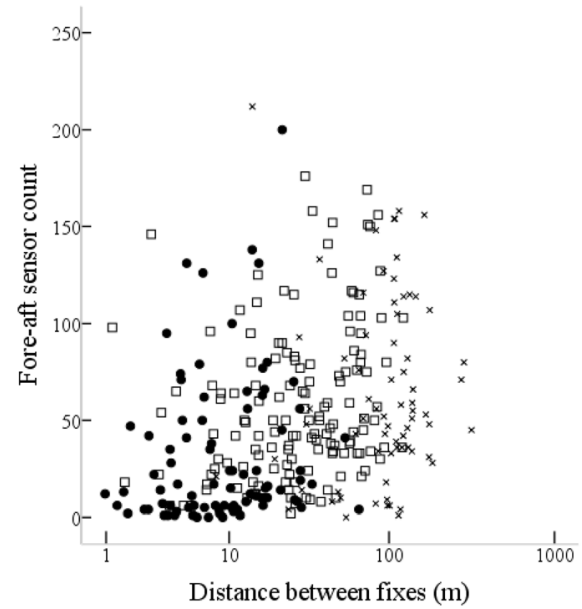

c.

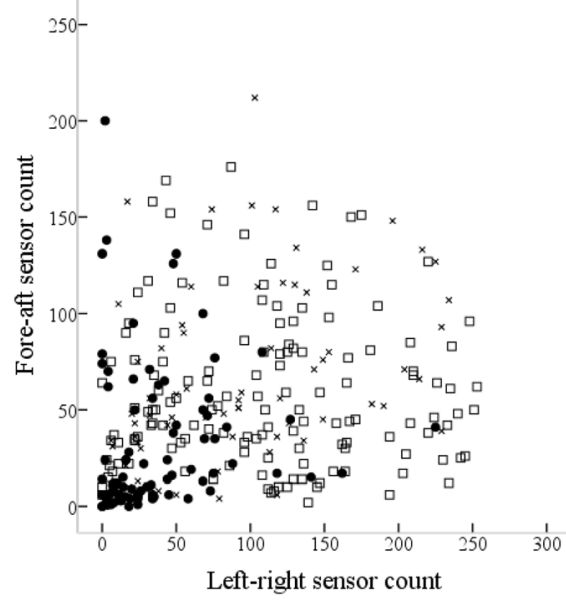

Fig. 2 Relationship between GPS collar variables and cattle activities: grazing, resting, and traveling for Bonsmara cows in South Texas.

The graphs show the relationships between distance between GPS fixes and the left-right sensor count (a) and fore-aft sensor count (b), and the relationship between fore-aft and left-right sensor counts (c)

\section{Herd spread}

Herd spread varied seasonally and was significantly greatest during summer and autumn and least during winter (Kruskal-Wallis test: $H_{3}=176.19, P<0.001$; Fig. $5 a)$. Herd spread ranged from $181.01 \mathrm{~m} \pm 9.44 \mathrm{SE}, N=$ 492 in the winter to $337.73 \mathrm{~m} \pm 12.10 \mathrm{SE}, N=442$ in the late summer. From spring to summer, herd spread significantly increased. This was followed by a small nonsignificant decline in autumn and then a large significant decrease during winter. Herd spread also varied by time of day, and overall was significantly smaller at midday $(225.35 \mathrm{~m} \pm 3.24 \mathrm{SE}, N=5569)$ than in the other measured time periods (Kruskal-Wallis test: $H_{3}=510.57, P<$ 0.001 , Fig. 5b). The early morning, late afternoon, and midnight periods showed very similar mean spread (271.75 $\mathrm{m} \pm 3.23 \mathrm{SE}, N=5569)$. The herd had the greatest spread in the early morning during summer and around midnight during winter (Fig. 6a). Within time periods, animal activity also affected herd spread. The spread of the cattle herd during traveling was significantly smaller $(P<0.01)$ than that during grazing or resting during late summer through early winter (Fig. $6 \mathrm{~b})$. The mean herd spread when traveling for these periods ranged from $135.28 \mathrm{~m} \pm 24.24 \mathrm{SE}(N=31)$ to $300.66 \mathrm{~m} \pm 18.79 \mathrm{SE}(N=213)$. The mean herd spreads during resting and grazing were similar in these periods and ranged from $201.35 \mathrm{~m} \pm 4.24 \mathrm{SE}, N=1869$ to $400.38 \mathrm{~m} \pm 8.12 \mathrm{SE}, N=996$. The herd spread was significantly greater $(P<0.01)$ during grazing or resting in late summer and late autumn than in any other combination of activity and season. Herd spread was smallest and most consistent for all three activities in the late winter and early spring. The mean herd spread, with all three activities combined, during these two periods was $160.46 \mathrm{~m} \pm 6.06 \mathrm{SE}, N=9057$.

\section{Temperature fluctuations and estimation of NDVI}

According to GPS collar temperature sensors, the summer season was the hottest of the year $\left(30.75^{\circ} \mathrm{C} \pm 0.07\right.$ $\mathrm{SE})$, followed by autumn $\left(25.14^{\circ} \mathrm{C} \pm 0.12 \mathrm{SE}\right)$ and then spring $\left(23.54{ }^{\circ} \mathrm{C} \pm 0.16 \mathrm{SE}\right)$, and winter was the coldest season $\left(18.77^{\circ} \mathrm{C} \pm 0.14 \mathrm{SE}\right)$. Midday appeared to be the hottest period of the day in all seasons, and was followed by late afternoon, whereas early morning and midnight were the coldest periods (Table 3 ).

Atmospherically corrected images showed that NDVI was significantly lower but different during the spring and winter, and higher during the summer and autumn, 


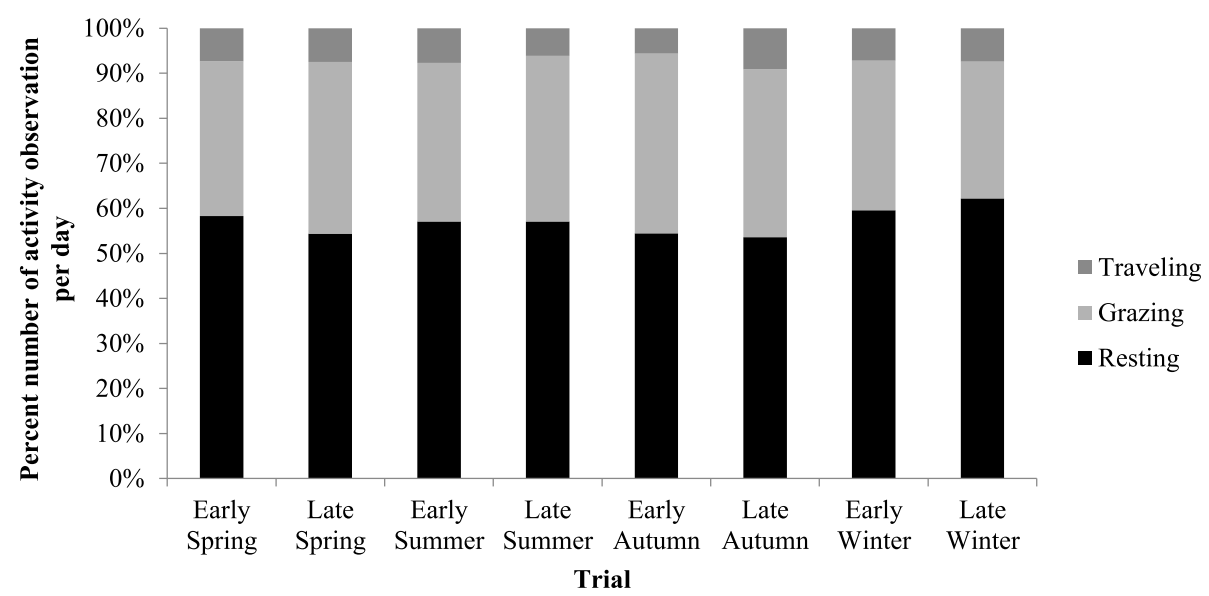

Fig. 3 Percentage and standard error of activity observations per day of a free-ranging cattle herd $(N=11)$ during eight trials of 21 days in a semi-arid rangeland. Activity observations occurred at a 5-min interval throughout $24 \mathrm{~h}$ days

with values ranging from $0.117 \pm 0.0086 \mathrm{SE}, N=256$ during spring to $0.306 \pm 0.016 \mathrm{SE}, N=256$ during autumn (ANOVA: $\left.F_{3,1020}=32.40, P<0.05\right)$.

\section{Seasonal and diurnal use of shade patches by cattle}

When we compared the percentage of GPS fixes in shade patches per day among seasons, we found that the lowest percentages occurred during spring $(24.61 \% \pm$ $1.18 \mathrm{SE}, N=43)$ and summer $(23.64 \% \pm 1.20 \mathrm{SE}, N=$ $42)$, and the highest percentages occurred during autumn $(31.59 \% \pm 1.36 \mathrm{SE}, N=35)$ and winter $(34.55 \% \pm$ 1.14 SE, $N=42$ ) (Kruskal-Wallis test: $H_{3}=18.98, P<$ 0.05; Fig. 7). In terms of periods of the day, for all seasons combined, we found that midday $(13.27 \% \pm 0.66$ SE, $N=162$ ) had the highest percentage of GPS fixes per day in shade patches, followed by early morning $(8.17 \% \pm 0.49 \mathrm{SE}, N=162)$, then by late afternoon $(6.48 \% \pm 0.45 \mathrm{SE}, N=162)$ and midnight $(6.24 \% \pm 0.55$ SE, $N=162$ ), both of which had significantly lower percentages of GPS fixes $\left(H_{3}=121.70, P<0.05\right.$; Fig. 7). A more in-depth analysis revealed some differences among time periods within each season $\left(H_{15}=167.72, P<0.05\right.$; Fig. 7). Specifically, during spring and summer, a significantly higher percentage of GPS fixes occurred during the early morning and midday than during the late afternoon and midnight periods. During winter, the highest percentage of GPS fixes in shade patches occurred during midday and midnight, whereas no differences between time periods were observed during autumn.

\section{Seasonal and diurnal use of water areas}

The percentage of GPS fixes per day $30 \mathrm{~m}$ around water locations was highest during winter and lowest during autumn, but this pattern was not significant across seasons when all time periods were combined $(9.67 \% \pm 0.70$ $\mathrm{SE}, N=33)$. However, when all seasons were combined, midday $(5.46 \% \pm 0.50 \mathrm{SE}, N=130)$ showed the highest percentage of GPS fixes per day $30 \mathrm{~m}$ around water locations, which was followed by early morning $(2.52 \% \pm$ $0.32 \mathrm{SE}, N=130)$ and late afternoon $(1.68 \% \pm 0.21 \mathrm{SE}$, $N=130)$, whereas midnight $(0.09 \% \pm 0.04 \mathrm{SE}, N=130)$ had the lowest percentage (Kruskal-Wallis test: $\mathrm{H}_{3}=$ 244.25, $P<0.05)$. A detailed analysis of the time periods within each season indicated significant differences among some time periods for all seasons $\left(H_{15}=257.14\right.$, $P<0.05$; Fig. 8). During spring and summer, the highest percentage of GPS fixes per day around water locations was found during midday and early morning hours, followed by late afternoon and midnight, which showed the lowest percentage. The autumn season showed a different pattern in which the midday, late afternoon, and early morning periods had significantly similar average numbers of GPS fixes per day around water locations, and that for midnight was significantly lower. Finally, winter showed a pattern similar to those of spring and summer, except that the midday and late afternoon periods had the highest average number of GPS fixes per day around water locations, followed by early morning, and no observations were found during the midnight period.

\section{Seasonal and diurnal use of supplemental feeding areas} Cattle were supplementary feed three times per week during late morning or early afternoon at one location each feeding time. Somewhat similarly to the overall seasonal pattern for use of water areas, winter had the highest percentage GPS fixes per day $30 \mathrm{~m}$ around feeding areas, and autumn had the lowest percentage, but it the difference was not significant across seasons $(11.80 \% \pm$ $0.78 \mathrm{SE}, N=33$ ). In terms of periods of the day, with all seasons combined, we found the same pattern as that observed for the water areas, wherein midday $(7.60 \% \pm$ 


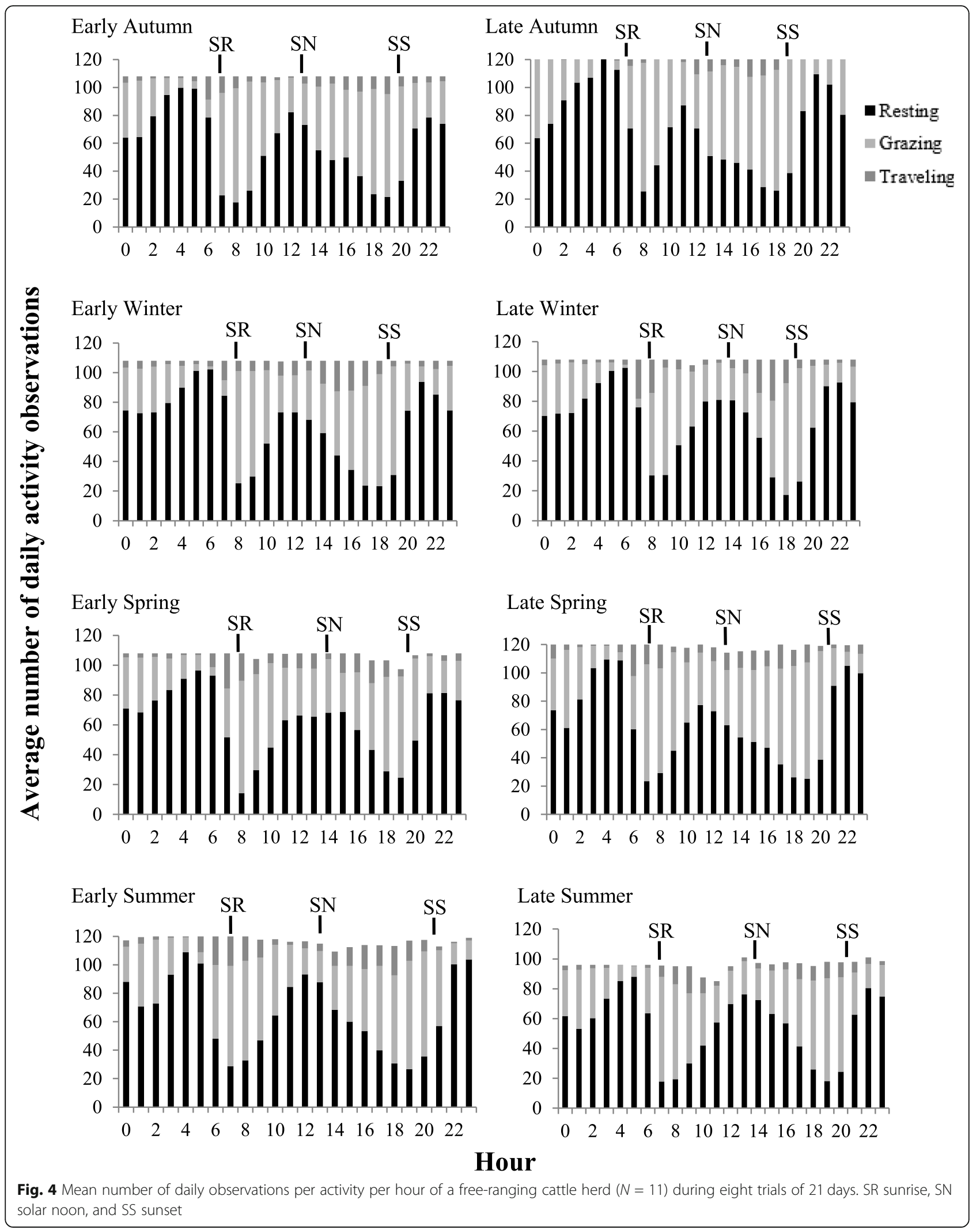




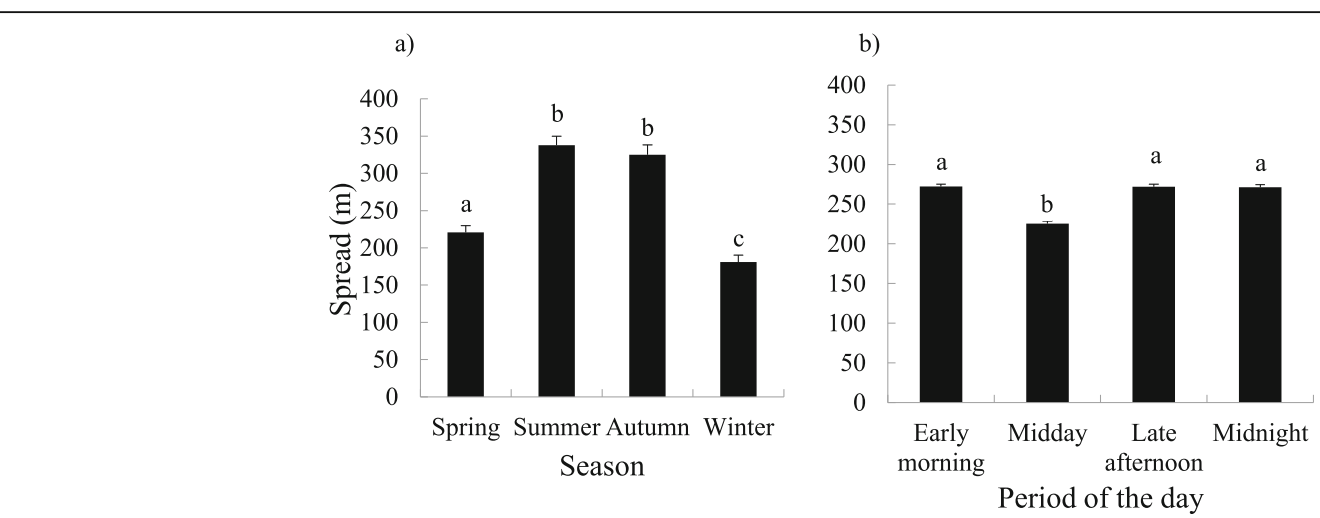

Fig. 5 Mean and standard error of the spread per season (a) and period of the day (b) of a free-ranging cattle herd ( $N=11)$ during eight trials of 3 weeks from September 2007 to August 2008. Periods of the day were selected as follows: (1) early morning, the first $3 \mathrm{~h}$ after sunrise; (2) midday, the $3 \mathrm{~h}$ around solar noon; (3) late afternoon, the last $3 \mathrm{~h}$ before sunset; and (4) midnight, the $3 \mathrm{~h}$ opposite from solar noon. Different letters above the bars indicate significant difference $(P<0.01)$

$0.51 \mathrm{SE}, N=133)$ showed the highest percentage of GPS fixes per day $30 \mathrm{~m}$ around feeding locations, followed by early morning $(2.60 \% \pm 0.30 \mathrm{SE}, N=133)$ and late afternoon $(1.95 \% \pm 0.24 \mathrm{SE}, N=133)$, and midnight $(0.49 \% \pm$ $0.13 \mathrm{SE}, N=133$ ) had the lowest percentage (KruskalWallis test: $\left.H_{3}=216.33, P<0.05\right)$. Differences were also observed among time periods within each season $\left(H_{15}=\right.$
239.97, $P<0.05$; Fig. 9). Similarly to the pattern observed around water areas, during spring, the highest percentage of GPS fixes per day around supplemental feeding areas was found during midday, followed by early morning and late afternoon, and midnight showed the lowest percentage. Summer exhibited a different pattern wherein the only significant and largest percentage

a)

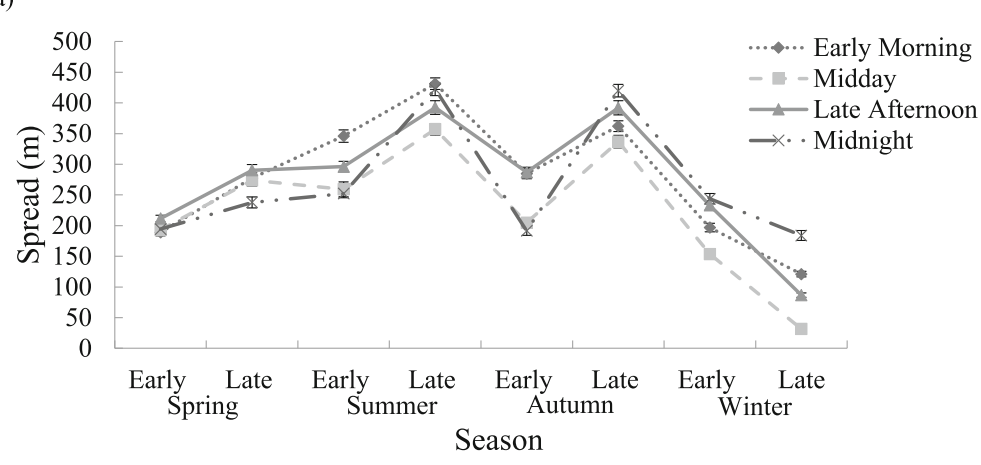

b)

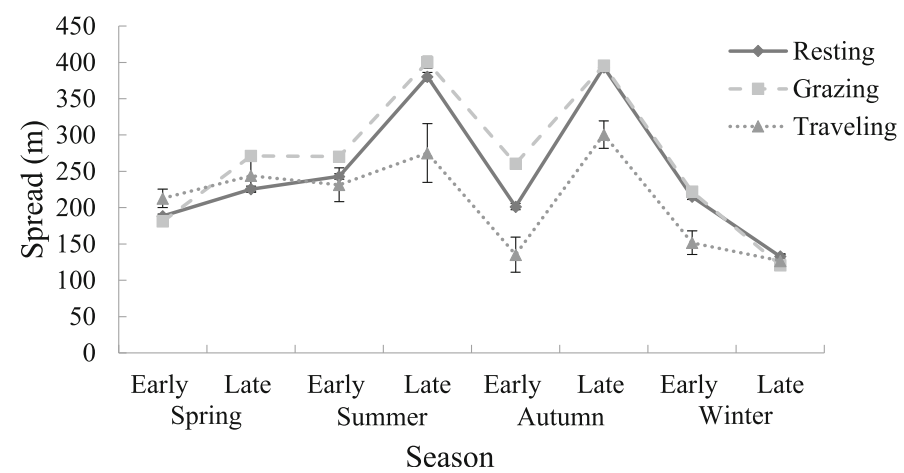

Fig. 6 Mean and standard error of the spread per period of the day (a) and activity (b) of a free-ranging cattle herd $(N=11)$ during eight trials of 3 weeks from September 2007 to August 2008 
Table 3 Mean and standard error of diurnal and seasonal temperatures $\left({ }^{\circ} \mathrm{C}\right)$ collected by the GPS collars

\begin{tabular}{cllll}
\hline Parameter & Early morning & Midday & Late afternoon & Midnight \\
\hline Spring & & & & \\
Mean & 19.54 & 29.08 & 28.16 & 17.36 \\
SE & 0.18 & 0.15 & 0.14 & 0.16 \\
Summer & & & & \\
Mean & 26.65 & 35.18 & 34.77 & 26.40 \\
SE & 0.07 & 0.08 & 0.09 & 0.04 \\
Autumn & & & & \\
Mean & 22.48 & 30.17 & 28.42 & 19.51 \\
SE & 0.14 & 0.08 & 0.11 & 0.14 \\
Winter & & & & \\
Mean & 13.28 & 24.24 & 24.13 & 13.43 \\
SE & 0.17 & 0.12 & 0.12 & 0.15 \\
\hline
\end{tabular}

of GPS fixes around feeding areas occurred during midday. During autumn, the same pattern was observed around water locations, in which midday, late afternoon, and early morning had significantly similar percentages of GPS fixes per day around supplemental feeding areas, and the midnight period percentage was lower. Finally, winter showed the highest percentage of GPS fixes per day around supplemental feeding areas during the midday and late afternoon, and early morning and midnight showed the lowest values.

\section{Discussion}

The cattle herd was more dispersed during the warm season, when vegetation was most abundant

At the seasonal scale, herd spread was greater during the warm growing season than the cold season, when forage was less abundant. Hence, in this study, as in other studies, the spread pattern appears to be partly explained by seasonal changes in available forage biomass, causing the

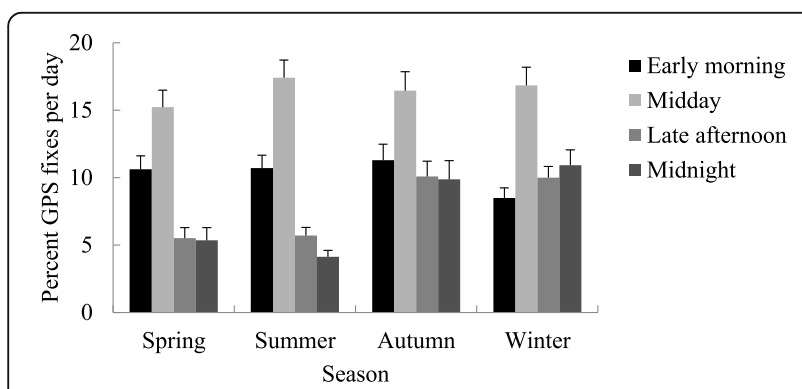

Fig. 7 Percentage and standard error of GPS fixes inside shade patches per day of a free-ranging cattle herd $(N=11)$ for each season and during four 3 -h time periods (early morning, midday, late afternoon, and midnight), by using positional data from eight trials of 3 weeks from September 2007 to August 2008 in a semi-arid rangeland in South Texas, USA

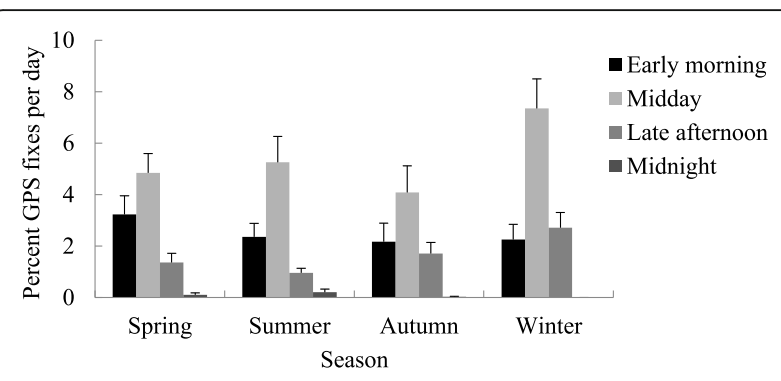

Fig. 8 Percentage and standard error of the number of GPS fixes 30 $\mathrm{m}$ around water locations per day of a free-ranging cattle herd $(N=$ 11) during four 3-h time periods for eight trials of 3 weeks from September 2007 to August 2008 in a semi-arid rangeland in South Texas, USA

dispersive movement during grazing, in which animals explore larger grazing areas, and subgroups tend to divide (Sato 1982; Owens et al. 1991; Cheleuitte-Nieves et al. 2018). This finding, however, contradicts those from studies on grazing cattle in northern, mountainous regions and other arid regions where cattle tend to forage and travel in larger and more compact groups during the summer, when forage is abundant, and disperse to search for sparser resources in winter (Dudzinski et al. 1982; Lazo 1994; Howery et al. 1996; Harris et al. 2002, 2007). Northern rangelands and the Southern Plains have different climate regimes, wherein seasonal peaks in precipitation, and temperature fluctuations influence forage growth patterns, thus affecting cattle distribution and activity schedules. The relationship between environmental variables and animal behavior is especially evident in hot, semi-arid environments, where sporadic and erratic precipitation leads to substantial fluctuations in forage quantity and quality, and heat loading strongly affects animal movement and activity patterns (Sowell et al. 1999). In semi-arid environments, vegetative production is often limited by soil moisture.

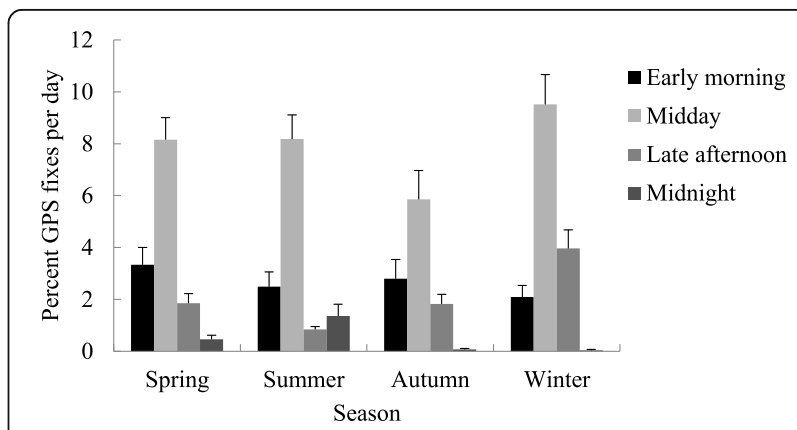

Fig. 9 Percentage and standard error of the number of GPS fixes 30 $\mathrm{m}$ around supplemental feed locations per day of a free-ranging cattle herd $(N=11)$ during four 3 -h time periods for eight trials of 3 weeks from September 2007 to August 2008 in a semi-arid rangeland in South Texas, USA 
In dry winter periods, cattle tend to congregate in riparian areas, which maintain higher quality and availability of herbaceous standing crop during the dry non-growing season. The semi-arid climate in our study site was characterized by the majority of precipitation occurring during the hot summer season; consequently, most of the forage growth occurred during this period. Hence, in the summer, when larger amounts of green forage are available, and animals are not as tied to widely dispersed water sources, the cattle can disperse and are more selective in their diet, thus resulting in greater herd spread and more homogeneous pasture utilization.

\section{The cattle herd was most congregated during midday, when the daily temperature was highest}

At the diurnal scale, herd spread was significantly lower during midday than the other time periods (early morning, late afternoon, and midnight) throughout the year. Previous studies have shown that the close associations of cattle during the hottest periods of the day are partly explained by thermoregulatory actions, wherein cows rest in compact groups under shade trees to lose heat and regulate body temperature (Coppock et al. 1986; DelCurto et al. 2000; Parsons et al. 2003; DelCurto et al. 2005; Cain III et al. 2006; Harris et al. 2007; Cooper et al. 2008). Midday is the hottest part of the day, and in South Texas, even winter midday temperatures can affect animal distribution. Thus, diurnal patterns of cattle herd distribution appear to be influenced by the interaction of diurnal fluctuations in temperature and thermoregulatory actions. An integrated analysis of both diurnal and seasonal patterns in this study revealed that during summer, herd spread was greatest in the early morning, which is the coolest time during daylight. This pattern might be associated with grazing periods, which occur primarily during the early morning and late afternoon, and tend to generate a dispersive movement throughout the pasture (Stricklin et al. 1976; Sato 1982; Scoones 1995; Ganskopp 2001; Parsons et al. 2003). In the winter, grazing activity was less influenced by high temperatures, and the greatest herd spread occurred around midnight, as animals either moved to keep warm or dispersed from the supplemental feeding sites. The differences in the diurnal variations in dispersion of the herd between the warm and cool seasons demonstrate how a strong seasonal component influences overall behavioral patterns.

\section{The cattle herd aggregated more during traveling than grazing or resting activities}

Herd spread was smaller during traveling than during resting and grazing, probably because of limitations in animal movement through the landscape (e.g., shrub density). Herd dispersive movement when grazing was probably due to the scattered nature of good forage resources in semi-arid environments. These activity patterns can have focused effects on the landscape through grazing and trampling (Bailey 1995; Bailey et al. 1996). For example, grazing can alter plant community structures, and intensive use of areas such as trails and shaded resting areas may lead to soil compaction and disrupt plant growth. In contrast, in productive pasture settings, the opposite pattern may be found, wherein cattle congregate to feed but disperse when moving to new areas (Shiyomi and Tsuiki 1999). In terms of animal activity patterns, we successfully discriminated resting, traveling, and grazing activities mainly according to the distance between the variable of GPS fixes, with a correct classification rate of $73 \%$. These results partially contrast with those of Ungar et al. (2005), who have suggested that the distance between GPS fixes is not a good predictor of activities. In addition, the cattle in this study spent a smaller proportion of time resting (28\%) and a larger proportion of time traveling (24\%) than the $49 \%$ resting and $10 \%$ traveling observed in a study conducted in Oregon and Israel (Ungar et al. 2005). Interactions among breed, terrain, climate, and vegetation characteristics might explain the differences in the proportions of time spent per activity in these studies (Kie and Boroski 1996; DelCurto et al. 2005). The topography in our study was gentle with scattered woody vegetation, in contrast to the hilly terrain with different forage dispersal patterns in previous studies (Howery et al. 1996; Harris et al. 2002). Therefore, distances between GPS fixes may be a good discriminator of activity in semi-arid rangelands with gentle topography but may be inappropriate for different environments where different animal and environment interactions occur.

At the seasonal scale, all trials showed a higher frequency of resting activity per day compared to grazing and traveling activities and traveling accounted for the lowest frequency of occurrence among all three activities throughout the year. These results show that cattle follow the similar frequency of activities regardless of season. At the diurnal scale, two grazing periods and two resting periods were identified that followed a similar pattern throughout the seasons, that is, a similar daily routine. Overall, the resting periods occurred during night time and around the solar noon which was determined to be the hottest period of the day and coincides with cattle aggregation in shade patches (see discussion below). Grazing periods occurred during the early morning and late afternoon. Thus, these patterns seem to follow sunrise, noon, and sunset schedules. The low frequency of the traveling activity which mainly occurred at the beginning and throughout grazing periods is most likely due to animal movements through grazing areas. Finally, a closer examination of activity schedules 
between seasons, a start-time shift in the activity periods can be observed which most likely follows the shift in daylight periods throughout the year. For example, during the winter season the first grazing period started at around 8:00, whereas the first grazing period during the summer season started earlier at 6:00. Furthermore, the peak of the second grazing period during winter occurred at around 18:00, whereas the peak during summer occurred at around 20:00.

\section{The cattle herd showed greater use of shade patches during the colder dry periods at the seasonal scale and during midday at the diurnal scale}

Shade patches were used more by our study herd during the autumn and winter seasons and less during the spring and summer seasons. These results contrast with those of previous studies reporting that during the summer, cows spend a larger amount of time under shade trees near water or aggregate to avoid flies, whereas the during winter, they spend most of their time at warmer exposures and avoid shade trees in a pasture in the dry tropics of Rockhampton, Queensland and experimental pastures in Japan (Sato 1982; Harris et al. 2002). In our study, the overall aggregation observed during the winter season might then be partly explained by congregation of animals in shade patches, although we expected this physiological response to occur during the hotter temperatures of the summer. However, shade affects more than just the cattle: typically, shade is provided by trees growing in slightly deeper soils. Although not directly tested in our work, differences in soils and the effect of shading reduce moisture loss from soils and vegetation; thus, more edible forage is likely to remain in shaded areas throughout the nongrowing season. Furthermore, the trees found in the shade areas can also serve as windbreaks particularly during colder periods of the year reducing the speed of cold wind, physiologic impact (e.g., thermoregulatory requirements), and stress on the animals (Quam et al. 1994; Olson et al. 2000). Hence, the use of shade patches appears to be a function of the animal response to the interactions among seasonal and diurnal fluctuations in temperature, nutritional requirements, and thermoregulatory actions.

During midday, which has the highest mean temperatures, we recorded the largest percentage of GPS fixes per day in shade patches, which was followed by early morning and then late afternoon and midnight. This evidence is consistent with findings from many other studies indicating that on a diurnal scale, large herbivores congregate in shade areas during the hottest periods of the day. This behavior is partly explained by thermoregulatory actions, wherein animals rest in compact groups under shade trees to lose heat and regulate body temperature (Sato 1982; Bennet et al. 1985; Lazo 1994; Coppock et al. 1986; DelCurto 2000; Parsons et al. 2003; Harris et al. 2002, 2007;
DelCurto et al. 2005; Cooper et al. 2008). Ungulates such as impala, wildebeest, zebra, and waterbuck have been observed to loaf in the shade during midday in South African woodland and savanna ecosystems (Hirst 1975). These results are further supported by the observed higher aggregation during midday than the other three time periods (early morning, late afternoon, and midnight). However, it is important to mention that, given the low but similar percent of GPS fixes within and around shade areas (6.2$8.2 \%$ ) during early morning, late afternoon, and midnight when all seasons were combined, animal proximity to these shade areas may have been the result of a random event and not a specific diurnal driver. Nevertheless, the larger use of shade patches during early morning was unexpected because this time period, together with late afternoon, is usually associated with grazing activities occurring in open pastures (Gary et al. 1967; Stricklin 1976; Scoones 1995; Ganskopp 2001; Parsons et al. 2003). We expected a higher relative use of shade patches during the midnight period, which is associated with resting/ sleeping activity. However, when we compared the midnight period across seasons, we found that winter had a significantly higher use of shade patches by cattle than summer. This behavioral pattern might be explained by two mechanisms observed in the field and in other studies. The higher use of shade patches during winter might be due to cold wind avoidance mechanisms, and the lower use of shade patches during the hotter summer season may be due to compensatory night-time feeding and energy conservation strategies in open pastures (Bennet et al. 1985; Scoones 1995). These mechanisms are also supported by the patterns observed during late afternoon, in which the use of shade patches was significantly lower during the spring and summer and higher during the winter. Here, animals might again be using the open areas of pasture at this time during the spring and summer, driven by moderate temperatures, and in the winter, driven by avoiding cold winds in shaded/sheltered areas (Sato 1982). The autumn season did not show a clear pattern of shade patch use among time periods because the animals transitioned to the winter pattern when the highest percentage of GPS fixes per day in shade patches was observed at midday, followed by midnight and late afternoon, and the lowest use of shade patches occurred during early morning. Hence, beyond the influence of shade patches during midday on the spatial distribution of cattle throughout most of the year, during winter, these patches appeared to have a major role in attracting animals during nighttime.

The cattle herd did not show a seasonal pattern of use of water and supplemental feed areas, but did show a higher use during midday than other periods of the day On a seasonal basis, there was no overall significant pattern of use of water and supplemental feed areas when 
all time periods were combined. Although water and, to a certain extent, feeding areas are known to greatly influence ungulate movement patterns, their effects appear to be overshadowed by the influence of shade patches when water or feed are not limiting. The placement of supplemental feed and water in our study occurred year-round, but given the low forage production characteristic of the dry winter season, we expected the cattle to be more responsive and to have a higher frequency of winter use of supplemental feeding areas and water to meet energetic demands (Sato 1982; Bennet et al. 1985; Lazo 1994; Coppock et al. 1986; DelCurto 2000; Parsons et al. 2003; Harris et al. 2002, 2007; DelCurto et al. 2005; Cooper et al. 2008). Ungulates such as cattle and caribou tend to congregate in nutrient rich areas, which maintain higher quality and availability of herbaceous standing crops than dry land rangeland during the dry non-growing season (Senft et al. 1987; Owens et al. 1991; Johnson et al. 2002). These winter patterns have been found in western rangelands of North America, where the distribution of cattle during the non-growing season is primarily influenced by the supplemental placement of water and feed (Kie and Boroski 1996; DelCurto et al. 2005). However, the aggregation during the winter season observed in our previous studies and the present study appears to be more associated with seasonal fluctuations in shade patch use rather than water and supplemental feed use.

On a diurnal basis, for all seasons combined, the animals exhibited the highest use of both water and supplemental feed areas during midday, followed by late afternoon and early morning, and midnight had the lowest amount of use. This pattern correlates with the diurnal fluctuations in temperatures of the time periods sampled in this study, wherein midday had the highest temperatures, followed by late afternoon, early morning, and finally midnight. The greater use of water sources during midday might be associated with physiological responses (e.g., osmoregulation) to high temperatures associated to this time period. This behavioral response has been documented in arid and semi-arid regions of tropical Africa (Coppock et al. 1986), rangelands of Australia (Dudzinski et al. 1982; Howery et al. 1996), southwest Spain (Lazo 1994), Tohoku in Japan (Sato 1982), rangelands of the western USA (DelCurto 2000; DelCurto et al. 2005; Parsons et al. 2003; Harris et al. 2007), and South Texas (Cooper et al. 2008). In addition, in semi-arid areas, tall trees that provide deep shade tend to be restricted to sites with additional water. The low use of these resources at midnight is consistent with findings from other studies indicating that resource use and grazing activity by cattle tend to be minimal during the dark hours, particularly during the winter season (Gary et al. 1967). We also found differences in the use of water and supplemental feed areas among some time periods within seasons. The use of supplemental feeding areas during midnight was significantly higher during the spring and summer seasons and lower during the winter. In addition, the supplemental feeding area use during late afternoon was significantly lower during the summer and higher during the winter. These findings further support previous evidence that during warmer seasons, animals shelter more during the day for thermoregulation and exhibit night-time feeding behavior (Bennet et al. 1985; Scoones 1995).

The use of water and supplemental feeding areas during autumn was similar for both resources where midday, late afternoon, and early morning periods had the same level of use and midnight being significantly lower. Given the moderate temperatures and the intermediate phase of forage dormancy characteristic of this season, cattle do not seem to have a diurnal differential preference of these resources and, thus present a more evenly distributed resource use. A noticeable pattern, although not always significant, is that during spring, the use of both water and supplemental feeding areas appears to be higher during early morning compared to late afternoon and then this pattern starts to shift as seasons progresses with the use during late afternoon being higher than early morning during winter. This relative shift in seasonal resource use between these two time periods might be related to the interaction between seasonal and diurnal fluctuations in temperature (Scoones 1995). Animals might prefer to use these resources earlier in the day during the warm season to avoid higher temperatures later in the day, and during the cold season, their strategy shifts to use these resources in the afternoon and take advantage of warmer exposures.

\section{Conclusion}

Our work on cattle in a large pasture quantified the influences of multi-scale interactions among seasonal forage production, diurnal temperature fluctuations, and resource use distribution on cattle dispersive-aggregative movement, thermoregulatory actions, and activity patterns in a brushy savanna environment. Diurnal ungulate herd spread in our study appeared to be governed by the overall seasonal pattern, owing to forage availability. Furthermore, the interaction between seasonal and diurnal temperature fluctuations and shade patch availability appeared to be highly influential when water and supplemental feed were not limiting. The use of shade patches was influenced by seasonal changes in forage biomass, and seasonal and diurnal fluctuations in temperature. Hence, although abiotic factors such as slope and distance to water are usually considered the primary determinants of grazing distribution patterns in ungulates, other microsite characteristics appear be more 
influential than previously acknowledged. Our study used 11 tracked Angus $\times$ Bonsmara cows in a 31member herd located in a 457-ha ranch; therefore, more studies are needed to determine whether these results are typical behaviors in larger herds and different breeds. Nevertheless, our results showed that using the techniques outlined in this study, such as seasonal and diurnal GPS animal tracking technology, GIS, and remote sensing data, multi-scale spatio-temporal dynamics of cattle distribution and activity patterns can be evaluated. The contrasting evidence of cattle spread patterns found between northwestern and southern rangelands in North America highlights the importance of addressing questions at both fine and broad temporal scales and under different environments to understand livestock herd behavioral patterns.

In terms of management implications, this study offers baseline information on the temporal and spatial dynamics of a cattle herd, from which better operation techniques may be developed and tested in the future. The observed smaller spread during the dry winter season associated with observed aggregation of individuals in water and supplemental feeding areas may be useful in determining the most critical times to provide supplemental resources and allocate them to areas not frequently used by cattle, thus stimulating the animals to visit unused sites during the non-growing season. Periodical rotations of water/feeding stations could promote the exploration of different areas by livestock, thus reducing the probability of developing a static or fixed spatial memory of predictable preferred sites at the landscape scale. The use of GPS tracking technology and geospatial management tools may aid in research on livestock movement dynamics and the development of management strategies more compatible with herd behavior.

\section{Abbreviations}

AUP: Animal Use Protocol; GPS: Global positioning systems; GIS: Geographic Information System; NDVI: Normalized Difference Vegetation Index

\section{Acknowledgements}

We thank the owners of the ranch for granting permission to conduct this study on their land. We thank Oscar Saucedo and staff for assistance in cattle management, Manuel Figueroa-Pagan for technical help, and students from Southwest Texas Junior College and Robert Castro-Natal for assistance in cattle behavioral observations. We are very grateful to Dr. Andrew B. Gill, who helped improve this manuscript. The study was conducted under Texas A\&M University System animal use protocol AUP 2007-167 approved 09/19/2007. C. Cheleuitte-Nieves was supported by Hispanic Leaders in Agriculture and the Environment (HLAE) fellowships, the Alfred P. Sloan Foundation, a Texas A\&M University Graduate Diversity fellowship, and a Tom Slick fellowship.

\section{Authors' contributions}

All authors made substantial contributions to the conception, design, and acquisition of data, and made significant contributions to the analysis and interpretation of the data. All authors were involved in drafting the manuscript and revising it critically for important intellectual content. CCN, HLPB, XBW, and SMC have given final approval of the version to be published; they take public responsibility for appropriate portions of the content; and they have agreed to be accountable for all aspects of the work in ensuring that questions associated with the accuracy or integrity of any part of the work are appropriately investigated and resolved.

\section{Funding}

Funding to C. Cheleuitte-Nieves was provided through Hispanic Leaders in Agriculture and the Environment ( $\mathrm{HLAE}$ ) fellowships, the Alfred P. Sloan

Foundation, a Texas A\&M University Graduate Diversity fellowship, and a Department of Ecosystem and Management (Texas A\&M University) Tom Slick fellowship.

\section{Availability of data and materials}

The datasets used and analyzed during the current study are available from the corresponding author on reasonable request.

\section{Ethics approval and consent to participate}

Animals used in this study studies were in good condition and met the Institutional Animal Care and Use Committee guidelines set by Texas A\&M University (AUP \# 2007-167)

\section{Consent for publication}

Not applicable

\section{Competing interests}

The authors declare that they have no competing interests.

\section{Author details}

'Department of Ecosystem Science and Management, Texas A\&M University, 2120 TAMU, 320 WFES Building, College Station, TX 77843-2138, USA

${ }^{2}$ Present address: Center of Comparative Medicine and Pathology, Memorial Sloan Kettering Cancer Center, Weill Cornell Medicine, and Hospital for Special Surgery, 408 East 69th Street, Z-913, New York, NY 10021, USA. ${ }^{3}$ Caesar Kleberg Wildlife Research Institute, Texas A\&M University-Kingsville, 700 University Blvd. MSC 218, Kingsville, TX 78363, USA. ${ }^{4}$ Texas A\&M AgriLife Research, 1619 Garner Field Road, Uvalde, TX 78801, USA

Received: 1 May 2020 Accepted: 8 July 2020

Published online: 20 July 2020

\section{References}

Ahmad F (2012) Spectral vegetation indices performance evaluated for Cholistan Desert. J Geogr Reg Plann 5:165-172

Bailey DW (1995) Daily selection of feeding areas by cattle in homogeneous and heterogeneous environments. Appl Anim Behav Sci 45:183-200

Bailey DW (2004) Management strategies for optimal grazing distribution and use of arid rangelands. J Anim Sci 82:147-153

Bailey DW (2005) Identification and creation of optimum habitat conditions for livestock rangeland. For Ecol Manag 58:109-118

Bailey DW, Gross JE, Laca EA, Rittenhouse LR, Coughenour MB, Swift DM, Sims PL (1996) Mechanisms that result in large herbivore grazing distribution patterns. J Range Manag 49:386-400

Belovsky GE (1984) Herbivore optimal foraging: a comparative test of three models. Amer Nat 124:97-115

Bennet IL, Finch VA, Holmes CR (1985) Time spent in shade and its relationship with physiological factors of thermoregulation in three breeds of cattle. Appl Anim Behav Sci 13:227-236

Birtwistle AN, Laituri M, Bledsoe B, Friedman JM (2016) Using NDVI to measure precipitation in semi-arid landscapes. J Arid Environ 131:15-24

Butt B (2010) Pastoral resource access and utilization: quantifying the spatial and temporal relationships between livestock mobility, density and biomass availability in southern Kenya. Land Degrad Dev 21:520-539

Cain JW III, Krausman PR, Rosenstock SS, Turner JC (2006) Mechanisms of thermoregulation and water balance in desert ungulates. Wildl Soc Bull 34: 570-581

Cheleuitte-Nieves C, Perotto-Baldivieso HL, Wu, XB, Cooper SM (2018) Association patterns reveal dispersal-aggregation dynamics among cattle in a South Texas rangeland, USA. Ecol Process 7:29. doi: https://doi.org/ https://doi.org/ 10.1186/s13717-018-0141-9

Cooper SM, Owens MK, Cooper RM, Ginnett TF (2006) Effect of supplemental feeding on spatial distribution and browse utilization by white-tailed deer in semi-arid rangeland. J Arid Environ 66:716-726 
Cooper SM, Perotto-Baldivieso HL, Owens MK, Meek MG, Figueroa-Pagan M (2008) Distribution and interaction of white-tailed deer and cattle in a semiarid grazing system. Agri Ecosyst Environ 127:85-92

Cooper SM, Scott HM, de la Garza GR, Deck AL, Cathey JC (2010) Distribution and interspecies contact of feral swine and cattle on rangeland in South Texas: implications for disease transmission. J Wildl Dis 46:152-164

Coppock DL, Ellis JE, Swift DM (1986) Livestock feeding ecology and resource utilization in a nomadic pastoral ecosystem. J Appl Ecol 23:573-583

Coulombe ML, Masse A, Cote SD (2006) Quantification and accuracy of activity data measured with VHF and GPS telemetry. Wild Soc Bull 34:81-92

de Solla SR, Bonduriansky R, Brooks RJ (1999) Eliminating autocorrelation reduces biological relevance of home range estimates. J Anim Ecol 68:221-234

DelCurto T, Johnson BK, Vavra M, Ager AA, Coe PK (2000) The influence of season on distribution patterns relative to water and resource use by cattle grazing mixed forested rangelands. Proceeding, Western section, American Society of Animal Science 51:171-175

DelCurto T, Porath M, Parsons CT, Morrison JA (2005) Management strategies for sustainable beef cattle grazing on forested rangelands in the Pacific northwest. Rangeland Ecol Manag 58:119-127

Dudzinski ML, Muller WJ, Low WA, Schuh HJ (1982) Relationship between dispersion behaviour of free-ranging cattle and forage conditions. Appl Anim Ethol 8:225-241

Frixell JM (1991) Forage quality and aggregation by large herbivores. Amer Nat 138:478-498

Ganskopp D (2001) Manipulating cattle distribution with salt and water in large arid-land pastures: a GPS/GIS assessment. Appl Anim Behav Sci 73:251-262

Ganskopp D, Cruz R, Johnson DE (2000) Least-effort pathways?: a GIS analysis of livestock trails in rugged terrain. Appl Anim Sci 68:179-190

Ganskopp DC, Johnson DD (2007) GPS error in studies addressing animal movements and activities. Rangeland Ecol Manage 60:350-358

Gary LA, Sherritt GW, Hale EB (1967) Behavior of Charolais cattle on pasture. Journal Series of the Pennsylvania Agricultural Experiment Station 3294:203206

Gates DM (1970) Characteristics of soil and vegetated surfaces to reflected emitted radiation. Proceedings of the 3 rd international symposium on remote sensing of environment, p 573-600

Goheen JR, Palmer TM, Keesing F, Riginos C, Young TP (2010) Large herbivores facilitate savanna tree establishment via diverse and indirect pathways. J Anim Ecol 79:372-382

Harris NR, Johnson DE, George MR, McDougald NK (2002) The effect of topography, vegetation, and weather on cattle distributions at the San Joaquin experimental range, California. Proceedings of the Symposium on Oak Woodlands 5:53-63

Harris NR, Johnson DE, McDouglad NK, George MR (2007) Social associations and dominance of individuals in small herds of cattle. Rangeland Ecol Manage 60:339-349

Hinch GN, Thwaites CJ, Lynch JJ, Pearson AJ (1982) Spatial relationships within a 678 herd of young sterile bulls and steers. Appl Anim Ethol 8:27-44

Hirst SM (1975) Ungulate-habitat relationships in a south African woodland/ savanna ecosystem. Wild Monogr 44:3-60

Howery LD, Provenza FD, Banner RE, Scott CB (1996) Differences in home range and habitat use among individuals in a cattle herd. Appl Anim Behav Sci 49: 305-320

Jensen JR (2005) Introductory digital image processing: a remote sensing perspective, 3rd edn. Prentice Hall, Upper Saddle River, New Jersey

Johnson CJ, Parker KL, Heard DC, Gillingham MP (2002) Movement parameters of ungulates and scale-specific responses to the environment. J Anim Ecol 71: 225-235

Kie JG, Boroski BB (1996) Cattle distribution, habitats, and diets in the Sierra Nevada of California. J Range Manag 49:482-488

Kunz H, Hemelrijk CK (2003) Artificial fish schools: collective effects of school size, body size, and body form. Artif Life 9:237-253

Launchbaugh KL, Howery LD (2005) Understanding landscape use patterns of livestock as a consequence of foraging behaviour. Rangeland Ecol Manage 58:99-108

Lazo A (1994) Social segregation and the maintenance of social stability in a feral cattle population. Anim Behav 48:1133-1141

Lotek (2006) Lotek Wireless, Inc. Small and midsize animals. GPS Location Systems User's Manual, Rev. $\mathrm{H}$.

Martiny N, Camberlin P, Richard Y, Philippon N (2006) Compared regimes of NDVI and rainfall in semi-arid regions of Africa. Int J Remote Sens 27:5201-5223
Martiny N, Richard Y, Camberlin P (2005) Interannual persistence effects in vegetation dynamics of semi-arid Africa. Geophys Res Lett 32:L24403

Mbow C, Fensholt R, Rasmussen K, Diop D (2013) Can vegetation productivity be derived from greenness in a semi-arid environment? Evidence from groundbased measurements. J Arid Environ 97:56-65

National Oceanic and Atmospheric Administration (2007) Continuously operating reference stations (CORS). https://www.ngs.noaa.gov/CORS/data.shtml. Accessed October 2008.

Olson BE, Wallander RT, Paterson JA (2000) Do windbreaks minimize stress on cattle grazing foothill winter range? Can J Anim Sci 80:265-272

Owens MK, Launchbaugh KL, Holloway JW (1991) Pasture characteristics affecting spatial distribution of utilization by cattle in mixed brush communities. J Range Manag 44:118-123

Parker KL, Barboza PS, Gillingham MP (2009) Nutrition integrates environmental responses of ungulates. Funct Ecol 23:57-69

Parsons CT, Momont PA, DelCurto T, Mclnnis M, Porath M (2003) Cattle distribution patterns and vegetation use in mountain riparian areas. J Range Manag 56:334-341

Perotto-Baldivieso HL, Cooper SM, Cibils AF, Figueroa-Pagán M, Udaeta K, Rubio CM (2012) Detecting autocorrelation problems from GPS collars data in livestock studies. Appl Anim Behav Sci 136:117-125

Peters DPC, Bestelmeyer BT, Herrick JE, Fredrickson EL, Monger HC, Havstad KM (2006) Disentangling complex landscapes: new insights into arid and semiarid system dynamics. BioScience 56:491-501

Peters DPC, Pielke RA, Bestelmeyer BT, Allen CD, Munson-McGee S, Havstad KM (2004) Cross-scale interactions, nonlinearities, and forecasting catastrophic events. Proc Natl Acad Sci 101:15130-15135

Quam V, Johnson L, Wight B, Brandle JR (1994) Windbreaks for livestock operations. Papers in Nat Resour 123. https://digitalcommons.unl.edu/ natrespapers/123. Accessed June 2020.

Reinhardt V (1983) Movement orders and leadership in a semi-wild cattle herd. Behaviour 83:251-264

Ricklefs RE (2001) The economy of nature, fifth edn. W.H. Freeman and Company, New York

Ritchie EG, Martin JK, Johnson CN, Fox BJ (2009) Separating the influences of environment and species interactions on patterns of distribution and abundance: competition between large herbivores. J Anim Ecol 78:724-731

Roy DP, Kovalskyy V, Zhang HK, Vermote EF, Yan L, Kumar SS, Egorov A (2016) Characterization of Landsat-7 to Landsat-8 reflective wavelength and normalized difference vegetation index continuity. Remote Sens Environ 185: $57-70$

Šárová R, Špinka M, Arias Panamá JL, Šimeček P (2010) Graded leadership by dominant animals in a herd of female beef cattle on pasture. Anim Behav 79: 1037-1045

Sato S (1982) Leadership during actual grazing in a small herd of cattle. Appl Anim Ethol 8:53-84

Scoones I (1995) Exploiting heterogeneity: habitat use by cattle in dryland Zimbabwe. J Arid Environ 29:221-237

Seagle SW, McNaughton SJ (1992) Spatial variation in forage nutrient concentrations and the distribution of Serengeti grazing ungulates. Landsc Ecol 7:229-241

Senft RL, Coughenour MB, Bailey DW, Rittenhouse LR, Sala OE, Swift DM (1987) Large herbivore foraging and ecological hierarchies. BioScience 37:789-795

Shiyomi M, Tsuiki M (1999) Model for the spatial pattern formed by a small herd in grazing cattle. Ecol Model 119:231-238

Sowell BF, Mosley JC, Bowman JPG (1999) Social behavior of grazing beef cattle: implications for management. In: proceedings of the American Society of Animal Science, Indianapolis, Indiana, 1-6 July 1999

Stephenson MB, Bailey DW, Jensen D (2016) Association patterns of visuallyobserved cattle on Montana, USA foothill rangelands. Appl Anim Behav Sci 178:7-15

Stricklin WR (1983) Matrilinear social dominance and spatial relationships among Angus and Hereford cows. J Anim Sci 57:1397-1405

Stricklin WR, Wilson LL, Graves HB (1976) Feeding behavior of Angus and Charolais-Angus cows during summer and winter. J Anim Sci 43:721-732

Swihart RK, Slade NA (1997) On testing for independence of animal movements. J Agric Biol Environ Stat 2:48-63

Taylor RB, Rutledge J, Herrera JG (1999) A field guide to common South Texas shrubs. Texas Parks and Wildlife Press, Austin

Texas Natural Resources Information System (2008) https://tnris.org/. 
Turner LW, Anderson M, Larson BT, Udal MC (2001) Global positioning systems (GPS) and grazing behavior in cattle. Livestock environment VI: proceedings of the 6th international symposium 640-650.

Turner LW, Udal MC, Larson BT, Shearer SA (2000) Monitoring cattle behavior and pasture use with GPS and GIS. Can J Anim Sci 80:405-413

Ungar ED, Henkin Z, Gutman M, Dolev A, Genizi A, Ganskopp D (2005) Inference of animal activity from GPS collar data of free-ranging cattle. Rangeland Ecol Manag 58:256-266

United States Department of Agriculture (1976) Soil survey of Uvalde County, Texas. Soil Conservation Service. https://www.nrcs.usda.gov/Internet/FSE_ MANUSCRIPTS/texas/TX463/0/Uvalde.pdf. Accessed August 2018.

United States Geological Survey (2010) https://landsat.usgs.gov/.

Wallace LL, Turner MG, Romme WH, O'Neill RV, Wu Y (1995) Scale of heterogeneity of forage production and winter foraging by elk and bison Landsc Ecol 10:75-83

Waser PM (1985) Spatial structure of mangabey groups. Int J Primatol 6:569-580 Weber KT, Burcham M, Marcum CL (2001) Assessing independence of animal locations with association matrices. J Range Manag 54:21-24

Weladji RB, Klein DR, Holand Ø, Mysterud A (2002) Comparative response of Rangifer tarandus and other northern ungulates to climatic variability. Rangifer 22:29-46

Wolfram Research (2007) Eric Weisstein's world of physics. Available at: http:/ scienceworld.wolfram.com/physics/CenterofGravity.html. Accessed April 2008

[ENVI] Environment for visualizing images (2009) Atmospheric correction module: QUAC and FLAASH user's guide v. 4.7. ITT visual information solutions.

\section{Publisher's Note}

Springer Nature remains neutral with regard to jurisdictional claims in published maps and institutional affiliations.

\section{Submit your manuscript to a SpringerOpen ${ }^{\circ}$ journal and benefit from:}

- Convenient online submission

- Rigorous peer review

- Open access: articles freely available online

- High visibility within the field

- Retaining the copyright to your article

Submit your next manuscript at $\boldsymbol{\nabla}$ springeropen.com 